ISSN 1991- 8690

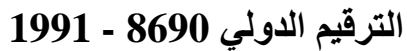

Website: http://jsci.utq.edu.iq

Email: utjsci@utq.edu.iq تأثير الأصابة بطفيلي المنشقة الدموية Schistosoma haematobium (Bilharz,1952) في أوزارن الجسم و الكبد و الطحال و الكليتين للفئران المختبرية Mus musculus

\author{
سندس جعفر رزاق \\ قسم علوم الحياة - كلية التربية - جامعة البصرة
}

أستُ عمل في الدراسة الحالية 80فأراً مختبرياً نوع Mus musculus سلالة BALB/c من كلا الجنسين (40 إناث و40 ذكور) كانت

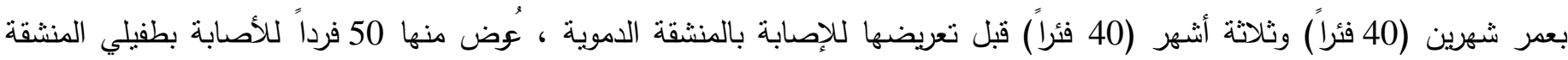

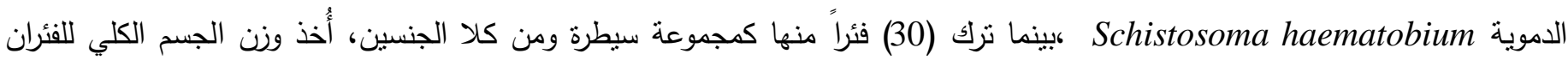
السليمة والمصابة بعد شهر وشهرين وثلاثة أثهر من الأصابة، رافقه تشريح الفئران وأخذ وزن الأعضاء الداخلية لها (الكبد والطحال والكليتين) التي يمر الطفيلي فيها خلال دورة حياته، أظهرت النتائج أن هناك تأثيراً للإصابة بهذا الطفيلي على أوزان الجسم والأعضاء قيد الدراسة مقارنة بالفئران السليمة، أذ أدت الإصابة إلى خفض وزن الجسم بصورة معنوية للفئات العمرية قيد الدراسة ولكلا الجنسين مقارنة بالسليمة منها والتي لها العمر نفسه ، بينما أدت الإصابة إلى تضخم في الطحال والكبد والكليتين الذي لوحظ من خلال الزيادة المعنوية في أوزانها للفئران المصابة بانية

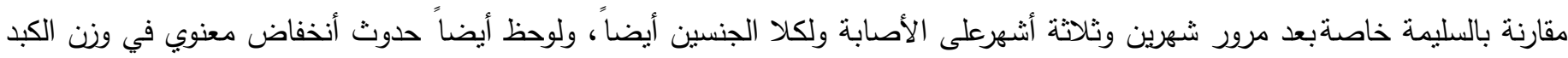

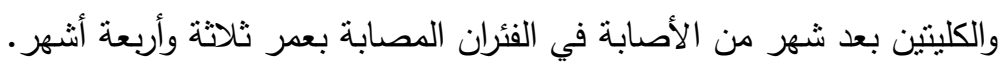

Key words: Schistosoma haematobium, Mice, Body weight, Liver weight, spleen weight, Kidney weight

بالمنشقة الدموية Schistosoma haematobium في 54 بلاً في أفريقيا وشرق البحر الأبيض المتوسط ومن ضمنها العراق

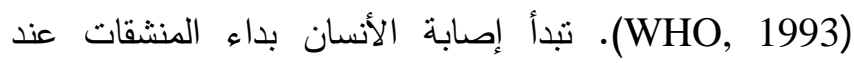
أختراق مذنبات المنشقة cercaria مشطورة الذنب لجلد المضيف لتهاجر عبر الأوعية الدموية بعد أن تفقد ذنبها متحولة إلى يافعة schistosomula Jones et. al., 2008; ) لتستقر فيه حوالي 97\% من اليافعات (Coulson and Wilson, 1987 ، تنغذى اليافعات هناك لوفرة (لتهات المواد الغذائية في الكبد والجهاز البابي الكبدي (Cox, 1982)
المقدمة: يتسبب داء البلهارزيا Bilharziases (أو داء المنشقات (Schistosomiases Sturrock,1993; Murray and ) Schistosoma المنشقة (Lopez,1996) ، أذ يقدر عدد المصابين بهذا المرض بحوالي 207 مليون شخص موزعين في أنحاء من العالم ويسبب بحوالي 280000 حالة وفاة سنوياً (WHO,2010; Gryseels et. al., ( 2006; van der Werf et. al., 2003) 


\section{المو اد وطر ائق العمل:}

جمعت القواقع نوع Bulinus truncatus المضيف الوسطي لطفيلي المنشقة الدموية S. haematobium من بعض الجداول في قضاء بلدروز في محافظة ديالى - العراق خلال شهري تموز وآب من العام 2001، وبعد التأكد من تصنيفها في المختبر

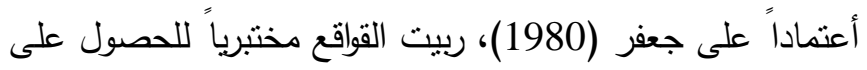
أفراد الجيل الثالث منها الذي عرض 50 فرداً منها للأصابة بمهدبات miracidia المنشقة الدموية. أختيرت في هذه الدراسة

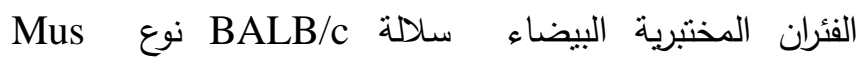
musculus للعمل المختبري وتحقيق هدف الدراسة ، أذ ربيت في البيت الحيواني التابع لقسم علوم الحياة بكلية التربية - جامعة البصرة في ظروف مختبرية مسيطر عليها من درجة حرارة وإضاءة وتغذية جيدة، وتم الحصول على الولادات الجديدة منها لإستخدامها في التجارب اللاحقة كونها معروفة الأعمارومسيطر على أصابتها بالأمراض الطفيلية إلى حد ما. تم الحصول على بيوض المنشقة الدموية من أدرار أطفال

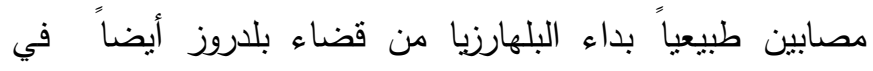
صيف عام 2002 ، أذ نم التأكد من أصابتهم بفحص الأدرار

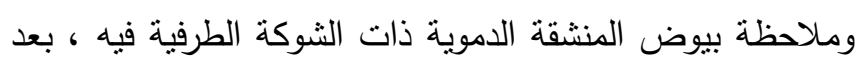
أجراء الترسيب على الأدرار واضافة المحلول الفسلجي ( normal (saline 0.85\% إلى الراسب منه، وضع الأخير في صندوق تلجي (ice box) وجلب إلى المختبر وتم أجراء عملية الطرد المركزي عليه لأخذ الراسب الحاوي على البيوض التي وضعت في دورق خاص للفقس ذو ذراع جانبي ومغلف بالسيلوفان بأستثناء الذراع الذي يسلط الضوء عليه لجذب المهدبات الفاقسة دوران

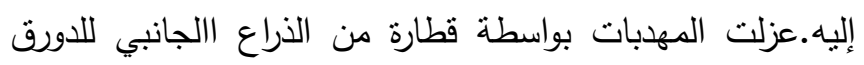
الخاص بالفقس وتم تعريض كافة القواقع من أفراد الجيل الثالث

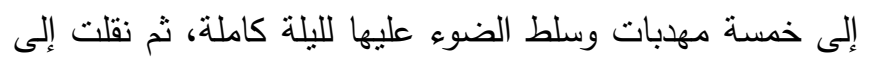
المختبر في الظروف الطبيعية للتربية. تمت أصابة الفئران

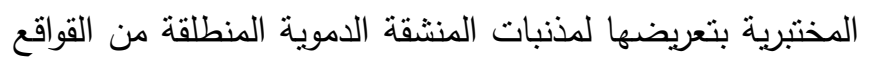
التي مر على أصابتها بمهدبات طفيلي المنشقة الدموية 28 -29 يوماً، أذ عرض 50 من ذكور وإناث هذه الفئران وكانت حينها
وتتمو هناك إلى ذكور وأناث حتى تتضج جنسياً وتتزاوج في الكبد

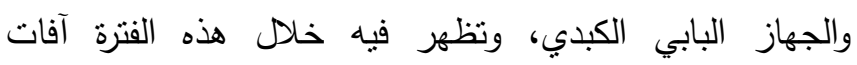

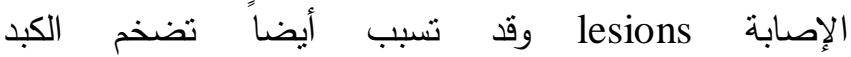
Abdel- ) splenomegaly والطحال hepatomegaly

.(Wahab et. al., 1992

تحمل ذكور المنشقة الدموية إناثها عبر الأوعية الدموية من

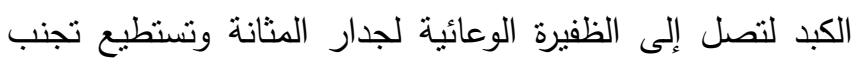

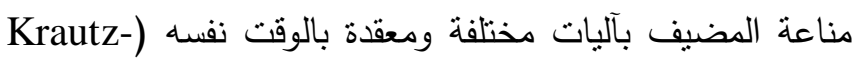
Peterson et. al., 2007; Pearce and MacDonald, 2002)، وعند وصولها هناك تبدأ الأناث بوضع أعداد كبيرة من البيوض ذات الشوكة الطرفية وتسمى هذه المرحلة من الأصابة

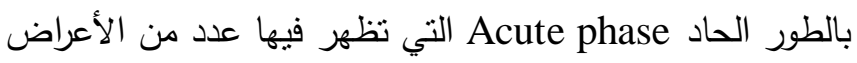
السريرية دنها الحمى والصداع وغنثان وتقيؤ وفقدان للشهية

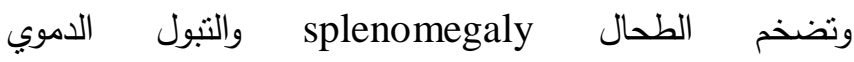
chronic haematuria phase وأستمرار التبول الدموي المصحوب بطرح كميات من البروتين proteinuria المتأخرة late chronic phase المتنظة بالأورام الحبييية وعسر التبول dysuria وفقدان الماء من الحالب والوحدات الأولية في bladder calcification الكلية وألتهاب الكلية وتكلس المثانة ونئة

وسرطانها bladder cancer) (WHO,1989) ونظراً لعدم وجود دراسة متخصصة سابقة في العراق تتاولت

Schistosoma تأثثرات الأصابة بطفيلي المنشقة الدموية haematobium والكليتين في الحيوانات المصابة بهذا الطفيلي ، لذا أجريت الدراسة الحالية على الفئران المختبرية سلالة BALB/c لمعرفية هذه التأثيرات بعد فترات زمنية مختلفة من الأصابة بأعتبارها الأجزاء التي يمر بها الطفيلي أثناء إصابة المضيف النهائي وما يتسبب من تأثيرات مرضية تلقي بضلالها على وزن جسم الاجزي المضيف بصورة عامة وبعض أعضاءه الحيوية بصورة خاصة. 
تم تحليل النتائج أحصائياً بأستعمال برنامج المعالج R.L.S.D. وأختبار أقل فارق معنوي معدلي الأحصائي spss بين الدنوسطات لجميع المعاملات لمعرفة الفروقات المعنوية.

أظهرت نتائج التحليل الأحصائي أن هناك فروق معنوية

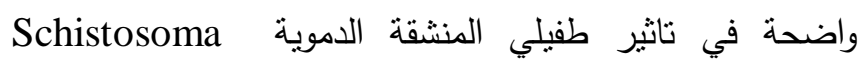

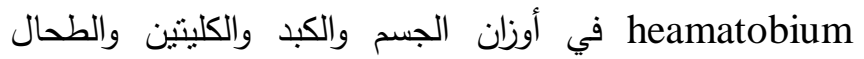
اللفئران المختبرية نوع Mus musculus سلالة BALB/c المصابة به مقارنة بالسليمة منها وبالفئات العمرية المختلفة ولكلا

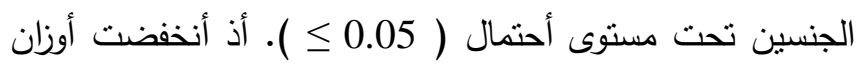

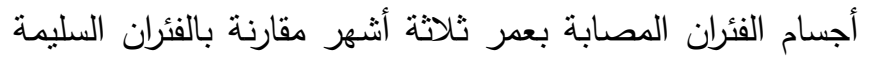

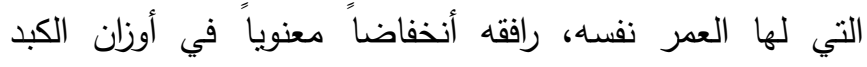

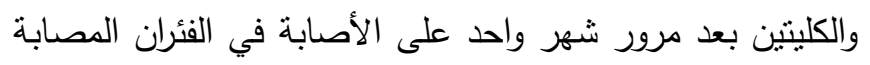

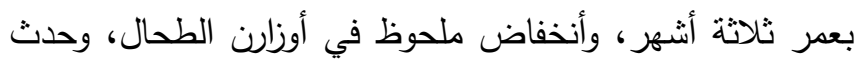

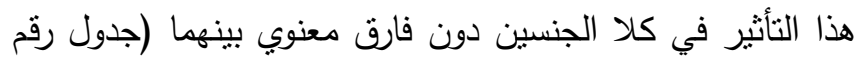

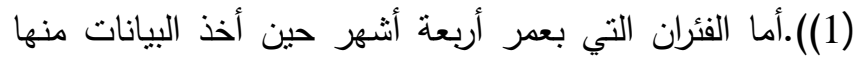

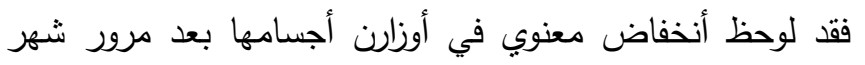

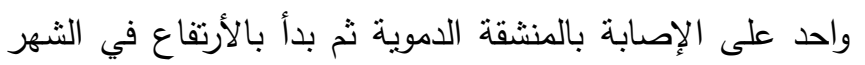

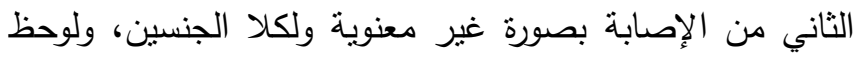

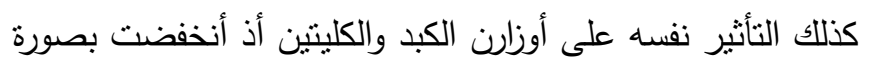

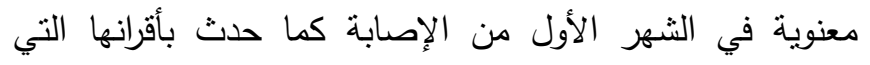
بعمر ثلاثة أثشهر وقت التجربة كما أسلفنا أعلاه، ثم عادت قيمها لأنا للإرتفاع في الثهر الثاني من الإصابة لتصل قريباً من الأوزارن الطيعية في مثلياتها السليمة ولكلا الجنسين. أما أوزارن الطحال الطيال

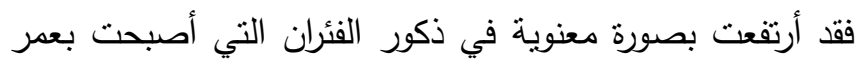
أربعة أشهر حينها، ولم تتأثر أوزان الطحال في الأناث بالفئة العمرية نفسها مقارنة بمثيلاتها السليمة (جدول رقم (2)). ونلاحظ في الجدول (3) الذي يمتل بيانات الفئران السليمة والمصابة بالمنثقة الدموية التي أصبحت بعمر خمسة أثنهر

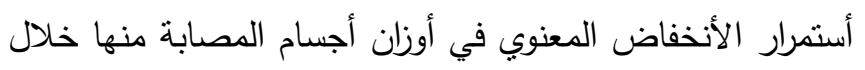

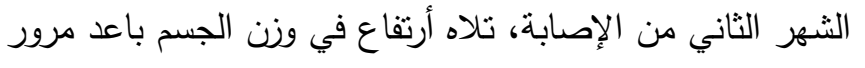

بعمر شهرين (30 فئراً) وثلاثة أشهر (20 فئراً) للأصابة للفترة من شهر أيلول إلى تثرين الأول من عام 2002 بأنباع الطريقة

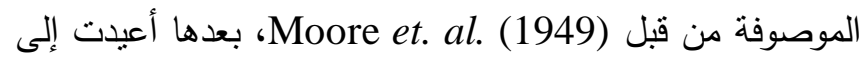
البيت الحيواني في الظروف المعيشية نفسها. أستعمل ثلاثون فأراً

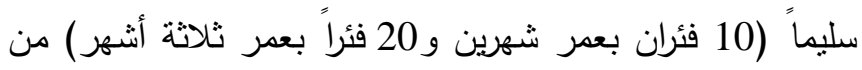
كلا الجنسين كمجوعة سيطرة وربيت في الظروف البيئية نفسها. جمعت البيانات بعد مرور شهر واحد وشهرين وثلاثة

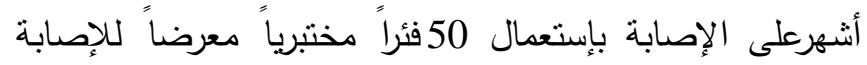
بمهدبات المنثقة الدموية (25 ذكور و 25 إناث) والتي كانت بعمر شهرين وثثلاثة أنثهر قبل الإصابة ، مع 30 فئراً مختبرياً

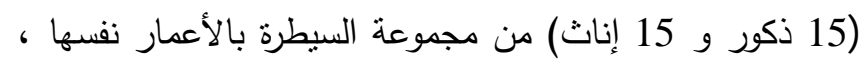
وأُشتخدم الأيثر في عمليات التخدير جميعها، أستعمل أولاً 40 فئراً

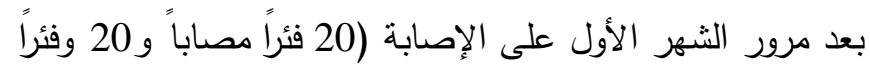
من مجموعة السيطرة) ومن كلا الجنسين وكان عمر الفئران في الإني حينها ثلاثة وأربعة أثشر لكلا المجموعتين المصابة والسليمة

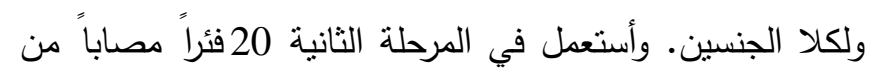

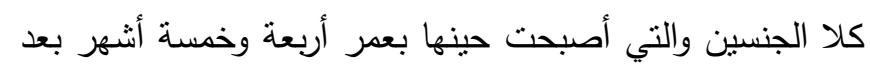

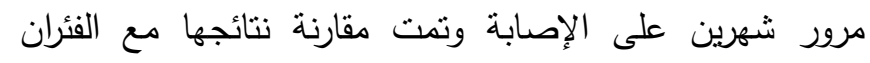
السليمة التي لها العمر نفسه والتي تم تثريحها في الثهر الأول

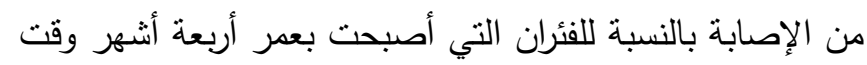

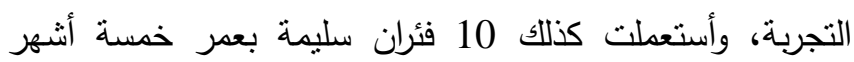

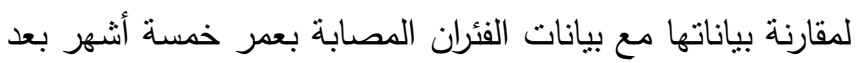
شهرين من الإصابة أ. وأخيراً أستعلت الإنة أ. 10 فئران مصابة من كلا الجنسين الني

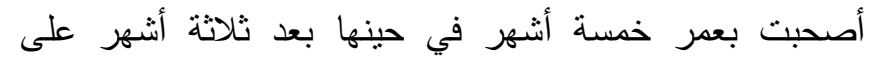

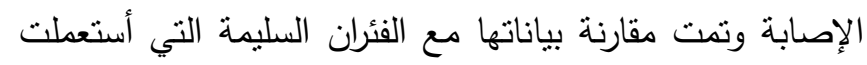
بعد شهرين على الإصابة، تضمنت البيانات تسجيل الأوزان الكلية للجسم بواسطة ميزان دقيق ثم شرحت وفحصت الفئران المعرضة الإنة للأصابة منها بمجهر النتريح للتأكد من أصابتها بالمنثقة الدموية

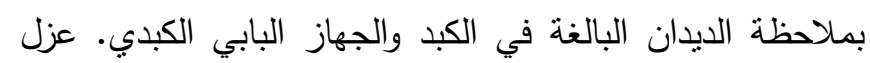

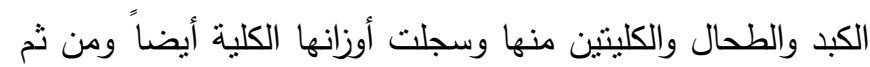
مقارنتها مع أوزان جسم وكبد وطحال وكليتات الفئران السليمة. 
الجنسين مقارنة بالفئران السليمة. أما أوزان الطحال فيها فقد

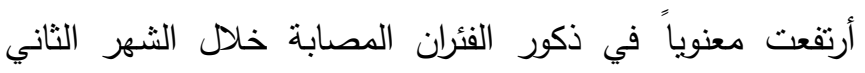
والثالث من الإصابة مقارنة بالفئران السليمة، ولم تتأثر أوزان الطحال في الأناث بالفئة العرية نفسها مقارنة بمثيلاتها السليمة.
الشهر الثالث على الإصابة مقترباً من القيم الطبيعية في الفئران

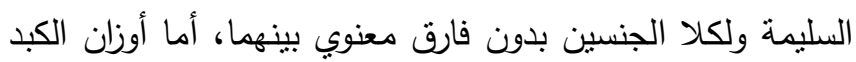

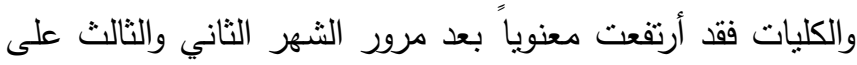
إصابة الفئران التي بعمر خمسة أثنهر حين أخذ البيانات ولكلا

جدول (1): أوزان الجسم والكبد و الطحال و الكليتين للفئر ان المختبرية السليمة والمصابة

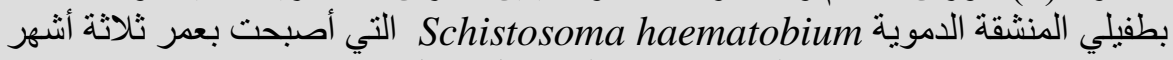
بعد مرور شهر واحد على الإصابة (القيم تمثل معدل اوزان خمسة حيو انات)

\begin{tabular}{|c|c|c|c|c|c|c|c|c|}
\hline \multicolumn{2}{|c|}{ وزثن انطحال (ثم) } & \multicolumn{2}{|c|}{ وزن الكنيتين (ثمث) } & \multicolumn{2}{|c|}{ ونن أكبد (ثم) } & \multicolumn{2}{|c|}{ وذن الجسم (غث) } & \multirow[b]{2}{*}{ | أجئس } \\
\hline ألمصنرائية & |انستُنيمة & |أمصنابة & |أنقنرانة & |المصنرابة & |القنتيمانة & |أمصنابة & |أنفئيمةانة & \\
\hline$\cdot, \cdot M A$ &., 098 &., 175 & $\cdot, \varepsilon 0\rceil$ & $\cdot, 10 \xi$ & $1,4 \cdot$ & $10, \mathrm{Y} \cdot$ & FV,Yo* & | الإنات \\
\hline$\cdot, \cdot V_{T}$ & 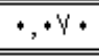 & $\cdot, 5 \varepsilon 1$ & .045 & $\cdot, y \varepsilon \varepsilon$ & 1,855 & $\{0, \varepsilon\} *$ & 5А, & الأنكور \\
\hline
\end{tabular}

جدول (2): أوزان الجسم و الكبد والطحال و الكليتين للفئر ان المختبرية السليمة و المصابة بطفيلي المنشقة

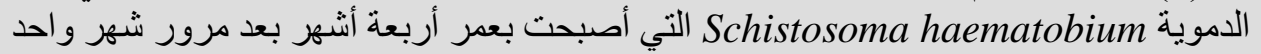
وشهرين على الإصابة (القيم تمثل معدل اوزان خمسة حيو انات)

\begin{tabular}{|c|c|c|c|c|c|c|c|c|c|c|c|c|}
\hline \multicolumn{3}{|c|}{ 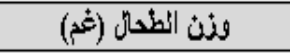 } & \multicolumn{3}{|c|}{ وزن الكيليتين (ثم) } & \multicolumn{3}{|c|}{ وئن الكبا (غُم) } & \multicolumn{3}{|c|}{ ونثن الجنم (ثم) } & \multirow{3}{*}{ | أجنس } \\
\hline \multicolumn{2}{|c|}{ 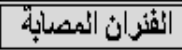 } & \multirow{2}{*}{ |أنقليمة } & \multicolumn{2}{|c|}{ |أفثران ا'مصائية } & \multirow{2}{*}{ أستيمية } & \multicolumn{2}{|c|}{ |أفثران ا'مصابية } & \multirow{2}{*}{ |أنقئيمة } & \multicolumn{2}{|c|}{ |أفثران ا'مصابة } & \multirow{2}{*}{ 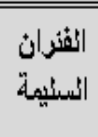 } & \\
\hline شهرين & شبه & & شهزين & شهيد & & شهرين & شهئ & & شهرين & بعد شهر & & \\
\hline । & $\cdot, \Pi \varepsilon \cdot$ & $\cdot, 11 \cdot$ & $\bullet, \varepsilon \cdot ५$ & • & $\cdot, 0 \leqslant A$ & $1, \lambda 55$ & $1,1 \cdot 1$ & $1,10 \varepsilon$ & $Y 1,1\rceil \varepsilon$ & $\Gamma, Y \backslash \wedge$ & $\Gamma 1,045$ & الإنات \\
\hline$\cdot, 1 \cdot \varepsilon$ & $\cdot, \mid \varepsilon \wedge$ & 4 & .015 & $\cdot, \Gamma \cdot \Lambda$ & \& & $1,05$. & $\cdot, 9 \vee \varepsilon$ & $1, y_{0}$. & $51,5 \backslash \varepsilon$ & $19,09 \varepsilon$ & $r \varphi, \lambda \varepsilon \cdot$ & الأنكور \\
\hline
\end{tabular}

جدول (3): أوز ان الجسم و الكبد والطحال والكليتين للفئر ان المختبرية السليمة و المصابة بطفيلي المنشقة الدموية Schistosoma haematobium

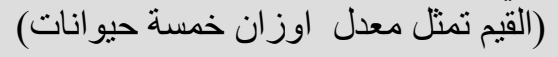

\begin{tabular}{|c|c|c|c|c|c|c|c|c|c|c|c|c|}
\hline \multicolumn{3}{|c|}{ وزن أطحال (ثُّم) } & \multicolumn{3}{|c|}{ 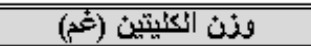 } & \multicolumn{3}{|c|}{ وذن أكبّا (غْم) } & \multicolumn{3}{|c|}{ ونذن الجسبم (غُم) } & \multirow[b]{3}{*}{ أجنّس } \\
\hline \multicolumn{2}{|c|}{ 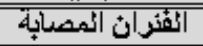 } & \multirow[b]{2}{*}{ ائسئليمة } & \multicolumn{2}{|c|}{ | } & \multirow[b]{2}{*}{ 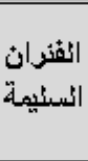 } & \multicolumn{2}{|c|}{ |فأفتران أمصابة } & \multirow[b]{2}{*}{ انسئيمة } & \multicolumn{2}{|c|}{ 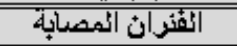 } & \multirow[b]{2}{*}{ النسئيمة } & \\
\hline أشلاثة & شهرين & & أشلاثة & شهرين & & أشلاثة & شهزين & & بَثد ثلاثية & شهيرين & & \\
\hline$\cdot, 5 \varepsilon V$ & $\cdot, r \cdot 9$ & $\cdot, 1 \cdot 7$ & $\cdot, \lambda \cdot 1$ & • & $\cdot, \varepsilon \vee A$ & $5,75 \%$ & $5,0 \leqslant 7$ & 5,55 & דר & $55,9 \times 7$ & $r \wedge, * \Lambda$ & الإنات \\
\hline$\cdot, M$ & $\cdot, 190$ & $\cdot, 17$. & $\cdot, M i$ & $\cdot, \times 11$ &., 09. & $5, \% 55$ & $5, \times 1$ & 1,091 & $5, q \cdot 5$ & $50,5 M$ & $\Gamma\urcorner, 0 \cdot \varepsilon$ & الألكور \\
\hline
\end{tabular}


زيادة معنوية في وزنه عما هو عليه في الفئران السليمة، وكذ

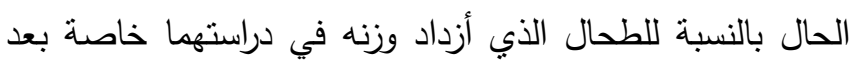
مرور ثلاثة أثهر فأكثر على الإصابة وهذا ما تم ملاحظته في

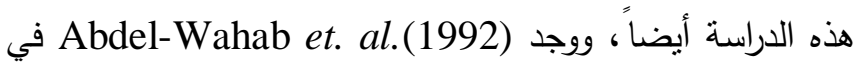
دراستهم على إصابات أطفال المدارس في مصر بالمنشقات المانسونية والدموية أن الإصابة بالمنثقة الدموية أدت إلى تضخم

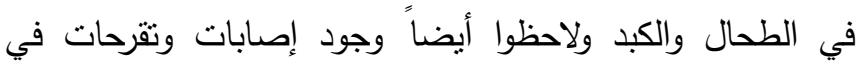
الكليتين لهؤلاء الأطفال أيضاً وتسبب الإصابة بالمنشقة دموية إلى الى

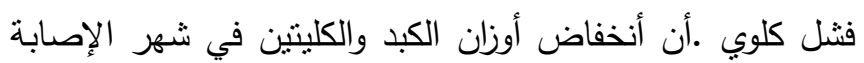

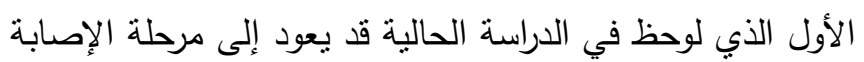

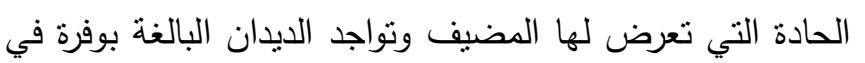

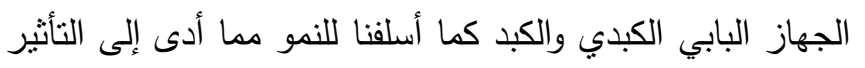

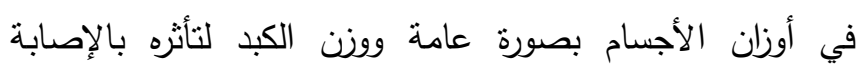

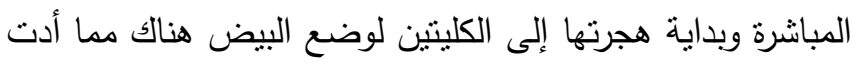

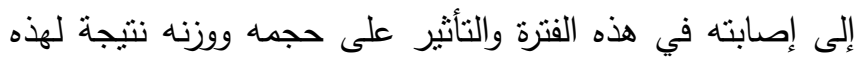

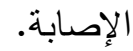

المصادر:

- جعفر ، أبر اهيم محمد (1980). القو اقع المائية في العر اق و التحري

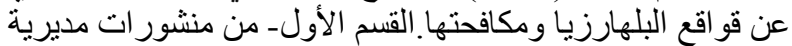
الأمر اض النوطنة بغداد ـ العراق.

-Abdel-Wahab, M. F.; Esmat, G.; Ramzy, I.; Fouad, R.; Abdel-Rahman, M.; Yosery, A.; Narooz, S. and Strickland G.T.(1992). Schistosoma haematobium infection in Egyptian schoolchildren: Demonstration of both hepatic and urinary tract morbidity by ultrasonography. Trans. Ro. Soc. Trop. Med. Hyg., 86:406-409.

-Coulson, P.S. and Wilson, R.A. (1987). An examination of the mechanisms of pulmonary phase resistance to Schistosoma mansoni in vaccinated mice. Am. J. Trop. Med. Hyg., 33:97-103.

-Cox, F.E.G. (1982). Modern parasitology: a text book of parasitology. Oxford; Boston: Blackwell Scientific Publications; St. Louis, Mo.:
وجناقفة:

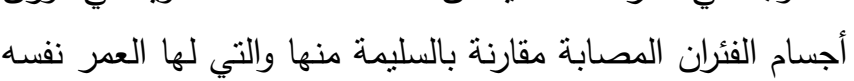

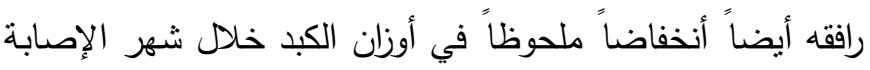

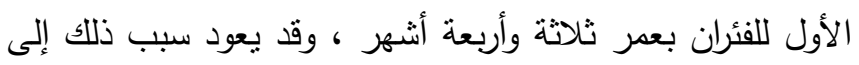
أن الديدان تصل إلى الجهاز البابي الكبدي كمحطة رئيسية في

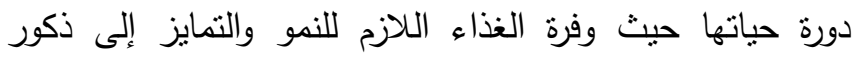

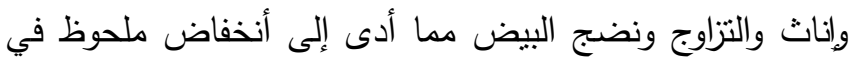

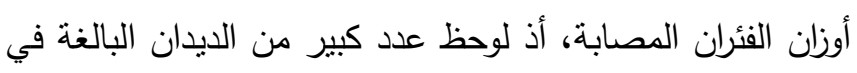

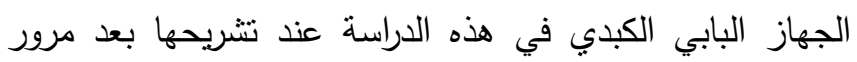

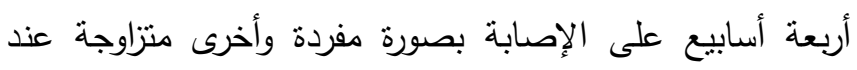

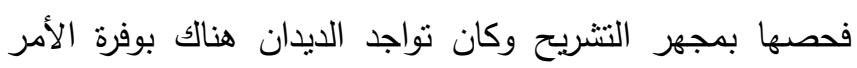
الذي قد يؤدي إلى أنخفاض كمية المغذيات الموزعة على أنحاء

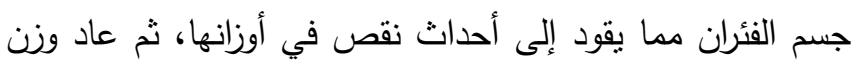

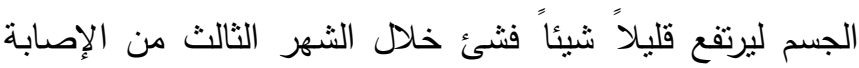
نتيجة لهجرة معظم الديدان البالغة إلى الظفيرة المثانية وأستقرارها

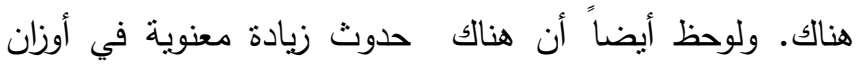
الكبد والطحال والكليتين خاصة بعد مرور شهرين وثنلاثة أثشر أثراك

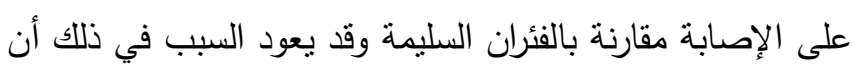

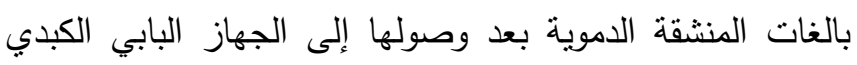

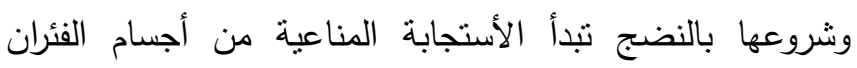

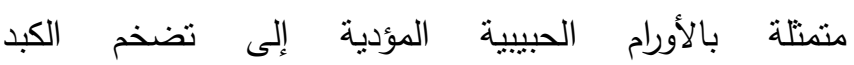
hepatomegaly

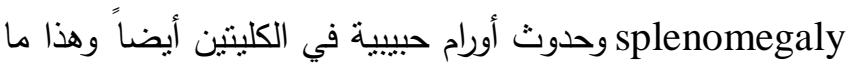

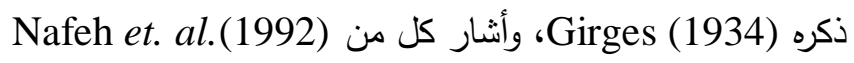

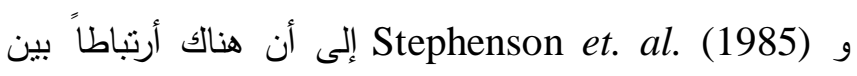

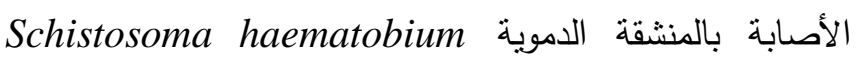
وتضخم الكبد والطحال في ألأطفال المصابين بداء المنثقة

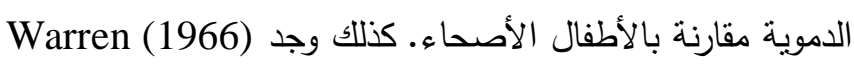
في دراسة أجراها على مائة فأر مختبري أبيض مصابة بالمنشقة

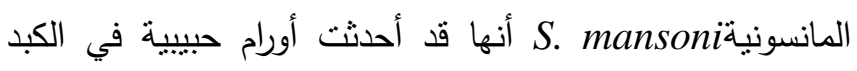

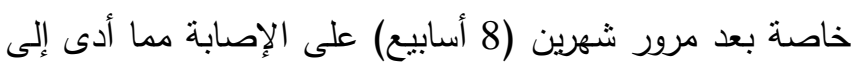


-Pearce, E.J. and MacDonald, A.S. (2002). The immunobiology of schistosomiasis. Nat. Rev. Immunol., 2: 499-511.

-Stephenson, L.S.; Latham, M.C.; Kinoti, S.N. and Oduori, M.L.(1985). Regression of Splenomegaly and Hepatomegaly in Children Treated for Schistosoma haematobium Infection. Am. J. Trop. Med. Hyg., 34: 119-123

-Sturrock, R. (1993). The parasites and their life cycles- S.intercalatum. In: Jordan, P.; Webbe, G. and Sturrock, R., (eds.). Human schistosomiasis. $8^{\text {th }}$ edition. Wallingford. UK: CAB International, 18-19.

-van der Werf, M.J.; de Vlas, S.J.; Brooker, S.; Looman, C.W.N.; Nagelkerke, N.J.D.; Habbema, J.D.F. and Engels, D. (2003). Quantification of clinical morbidity associated with schistosome infection in sub-Saharan Africa. Acta Trop., 86: 125-139.

-Warren, K.S. (1966).The pathogenesis of Clay-Pipe Stem Cirrhosis in mice with chronic schistosomiasis mansoni with a note on the longevity of the schistosomes. Am. J. Pathol., 49:477-489.

- WHO, (1989). Progress in assessment of morbidity due to schistosomiasis. Reviews of recent literature Document published by WHO Parasitic Diseases Programme Mott, K.E., Chen, M.G. WHO Press, Vol. 86, pp.155.

-WHO, (2010). Schistosomiasis: Report of WHO expert committee. http://www.who.int/mediacentre/factsheets/fs11 5/en/index.html
Distributors, USA, Blackwell Mosby, Edinburgh, pp.323.

-Girges, R. (1934). Schistosomiasis (bilharziasis). Bale, London, UK. pp.529.

-Gryseels, B.; Polman, K.; Clerinx, J. and Kestens, L. (2006). Human schistosomiasis. The Lancet, 368:1106-1118.

- Jones, M.K.; Lustigman, S. and Loukas, A. (2008). Tracking the odysseys of juvenile schistosomes to understand host interactions. PLoS Negl. Trop. Dis., 2: e257.

-Krautz-Peterson, G.; Camargo, S.; Huggel, K.; Verrey, F.; Shoemaker, C.B. and Skelly, P.J. (2007). Amino acid transport in schistosomes: characterization of the permease heavy chain SPRM1hc. J. Biol. Chem., 282: 21767-21775.

-Moore, D.V.; Yolles, T.K. and Meleney, H.E. (1949). A comparison of common laboratory animals as experimental hosts for Schistosoma mansoni. J. Parasitol., 35:156-170.

-Murray, C.J.L. and Lopez, A.D. (1996). EvidenceBased Health Policy-Lessons from the Global Burden of Disease Study. Science, Harvard University Press. Vol. 274: pp. 740-743

-Nafeh, M.A.; Medhat, A.; Swifae, Y.; Moftah, F.M.; Mohamed, A.; Soliman, A.A. and Strickland, G.T. (1992). Ultrasonographic change of the liver in Schistosoma haematobium infection. Am. J. Trop. Med. Hyg., 47:225-230.

-WHO, (1993). The control of schistosomiasis: Report of WHO expert committee. WHO Tech. Rep. Ser. Geneva. No. 830, 83 pp. 


\title{
Effect of the infection with Schistosoma haematobium (Bilharz, 1952) on Body, liver, spleen and kidney weight of laboratory Mus musculus mice
}

\author{
Sundus J. Razak \\ Department of Biology - College of Education - University of Basrah
}

\begin{abstract}
:
About 80 laboratory mice type BALB/c (40 male and 40 female) in age two months (40 animals)and three months (40 animals) before infection with Schistosoma haematobium were it are used in this study, 30 of these animals as a control group, and 50 of these were infected by cercaria of $S$. haematobium, the body wieght of infected and uninfected mice were measured after one, tow and three months of infection, and the weight of internal organs (liver, spleen and kidney) were measured in the same period as above. The results showed there was effect of infection on weight of body and other organs compared with uninfected mice. The body weight of infected mice was decreased compared with uninfected animals in all study period and in both genera that had the same age. Therefore, the liver, spleen and kidney weight were increased in infected animals especially in the second and third month of infection in. while the weight of liver and kidney of infected mice were decreased in the first month of infection compared with uninfected mice.
\end{abstract}

